\title{
Liquid-Phase Oxidation of Ethylene Glycol on Pt and Pt-Fe Catalysts for the Production of Glycolic Acid: Remarkable Bimetallic Effect and Reaction Mechanism
}

\author{
Honghong Shi, ${ }^{\S, \dagger}$ Xiaogang Yin, ${ }^{\S, \ddagger}$ Bala Subramaniam, ${ }^{\dagger}$ and Raghunath V. Chaudhari* ${ }^{\dagger}{ }^{\dagger}$ \\ ${ }^{\dagger}$ Department of Chemical \& Petroleum Engineering, University of Kansas, Lawrence, Kansas 66047, United States \\ ${ }^{\ddagger}$ Department of Chemistry \& Material Science, Guizhou Normal University, Guiyang, Guizhou 550001, China \\ Supporting Information
}

\begin{abstract}
A highly active and selective Pt-Fe alloy catalyst on $\mathrm{CeO}_{2}$ support is reported in this work for aqueous phase oxidation of ethylene glycol (EG) to glycolic acid. The Pt-Fe nanoparticles are highly alloyed with a face-centered cubic (fcc) type of crystal structure and a chemical state of $\mathrm{Pt}^{0} / \mathrm{Fe}^{0}$, as confirmed from X-ray diffraction and extended $\mathrm{X}$-ray absorption fine structure characterizations, respectively. Compared to the monometallic $\mathrm{Pt}$ catalyst, the $\mathrm{Pt}-\mathrm{Fe}$ catalyst shows more than a 17-fold higher initial TOF, while achieving complete EG conversion in $4 \mathrm{~h}$ at $70{ }^{\circ} \mathrm{C}$ and ambient $\mathrm{O}_{2}$ pressure under alkaline conditions. The synergistic bimetallic effect occurs due to significantly changing the $\mathrm{O}_{2}$ adsorption-dissociation characteristics on the catalyst surface. The addition of a base shows a promotional effect on both $\mathrm{Pt}$ and $\mathrm{Pt}-\mathrm{Fe}$ catalysts at low $\mathrm{NaOH}$ concentrations but an inhibition effect is observed for both catalysts at sufficiently high $\mathrm{NaOH}$ concentrations. Furthermore, the base enhances the synergistic effect observed with $\mathrm{Pt}-\mathrm{Fe}$ catalyst.

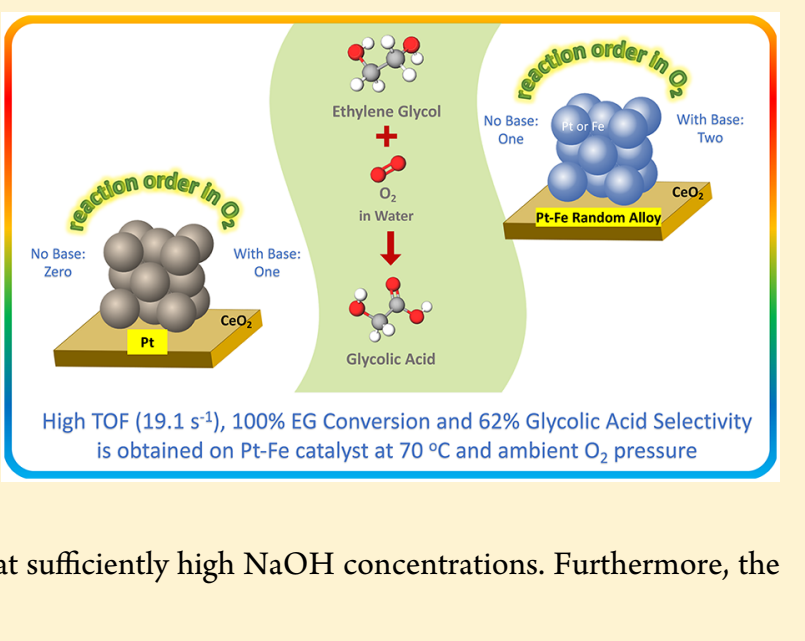

\section{INTRODUCTION}

The aqueous phase oxidation of biomass-derived sugars/ polyols to carboxylic acids is of great practical importance, because it offers a safer, greener, and potentially more economical route, compared to conventional processes using petroleum feedstocks. ${ }^{1}$ While numerous reports on glycerol or glucose oxidation have been published in recent years, ${ }^{2-4}$ the oxidation of ethylene glycol (EG) has not been extensively studied for the production of carboxylic acids (glycolic acid or oxalic acid).

As the simplest diol, EG is synthesized via the hydration of ethylene oxide or the hydrogenolysis of biomass. ${ }^{5}$ It is mainly used as a precursor for the manufacture of polyesters and as an antifreeze/coolant in automobiles and aircrafts. Significant research work has been reported on the electro-oxidation of EG, because of its higher boiling point $\left(189^{\circ} \mathrm{C}\right)$ and higher energy density, compared to ethanol and methanol. However, in this fuel cell application, EG is preferably converted to $\mathrm{CO}_{2}$ in order to harvest the maximum amount of energy. Partial oxidation of EG in the gas phase with $\mathrm{O}_{2}$ on $\mathrm{Ag}$ and $\mathrm{Cu}$ catalysts has been demonstrated to be the most economical and feasible pathway for the synthesis of glyoxal. ${ }^{6-8}$ Glycolic acid can also be produced from the aqueous-phase oxidation of EG selectively on the monometallic $\mathrm{Au},{ }^{9,10} \mathrm{Pd},{ }^{11} \mathrm{Ni},{ }^{12} \mathrm{Cu},{ }^{12}$ and $\mathrm{Pt}^{13,14}$ catalysts, but with low activity. The 5\% $\mathrm{Pd}-1 \%$ $\mathrm{Au}^{11}$ and $4.5 \% \mathrm{Pt}-0.5 \% \mathrm{Pd}^{14}$ catalysts have been reported to show bimetallic synergy in accelerating the oxidation rate, compared to the monometallic catalyst. However, little information was provided regarding the reaction mechanism.

The promotional effect of the addition of a transition metal to platinum metal for alcohol and $\mathrm{CO}$ oxidations has been reported in many publications. ${ }^{1-6}$ In this regard, the oxyphilic character of iron, with its high $\mathrm{O} / \mathrm{OH}$ binding energy, makes it an attractive metal to partner with platinum in order to enhance catalytic activity. Based on this hypothesis, we synthesized bimetallic $\mathrm{Pt}-\mathrm{Fe}$ catalyst and tested it for EG oxidation. The $\mathrm{CeO}_{2}$-supported catalysts are reported to exhibit excellent metal dispersion and catalytic behavior in oxidation reactions, ${ }^{15,16}$ because of the redox properties and the high lability of lattice oxygen in $\mathrm{CeO}_{2}$. Therefore, $\mathrm{CeO}_{2}$ was selected as the support material for the synthesis of heterogeneous $\mathrm{Pt}-\mathrm{Fe}$ catalyst in this study. Parametric effect studies were performed for aqueous-phase oxidation of EG over Pt and Pt-Fe catalysts under both neutral or alkaline conditions to provide insights into the underlying bimetallic effect and the role of alkali promoter.

Received: June 24, 2019

Revised: September 4, 2019

Accepted: September 12, 2019

Published: September 12, 2019 

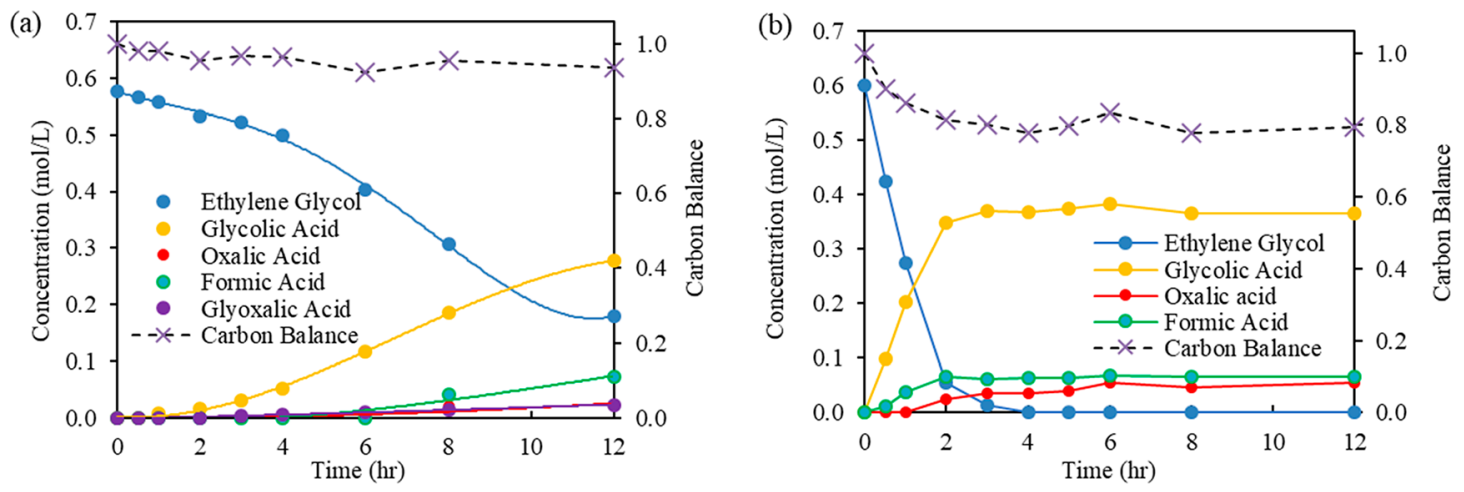

Figure 1. Concentration-time profiles on (a) $\mathrm{Pt} / \mathrm{CeO}_{2}$ and (b) $\mathrm{Pt}-\mathrm{Fe} / \mathrm{CeO}_{2}$ catalysts for aqueous phase EG oxidation in the presence of alkali promoter. Reaction conditions: initial EG concentration $=0.58 \mathrm{~mol} / \mathrm{L}$, initial $\mathrm{pH}=13.9$ (alkali added), EG:metal ratio $=5657: 1(\mathrm{~mol}: \mathrm{mol}), 70{ }^{\circ} \mathrm{C}$, $1 \mathrm{~atm} \mathrm{O}_{2}, 60 \mathrm{std} \mathrm{mL} / \mathrm{min}$.

Table 1. EG Oxidation over Pt and Pt-Fe Catalysts under Alkaline and Neutral Conditions

\begin{tabular}{|c|c|c|c|c|c|c|c|c|c|}
\hline & & \multirow[b]{2}{*}{$\begin{array}{l}\text { initial turnover frequency, } \\
\operatorname{TOF}_{\mathrm{EG}}{ }^{a}\left(\mathrm{~s}^{-1}\right)\end{array}$} & \multirow[b]{2}{*}{$\begin{array}{l}\text { conversion, } \\
\mathrm{X}^{b}(\%)\end{array}$} & \multicolumn{5}{|c|}{ Selectivity, $S(\%)^{b}$} & \multirow[b]{2}{*}{$\begin{array}{l}\text { carbon balance, } \\
\mathrm{CB}^{b, c}(\%)\end{array}$} \\
\hline & & & & $\begin{array}{l}\text { glycolic acid, } \\
\text { GLY }\end{array}$ & $\begin{array}{l}\text { glycolaldehyde, } \\
\text { GLA }\end{array}$ & $\begin{array}{l}\text { oxalic acid, } \\
\text { OA }\end{array}$ & $\begin{array}{l}\text { formic acid, } \\
\text { FA }\end{array}$ & others & \\
\hline \multirow[t]{2}{*}{$\mathrm{Pt}$} & alkaline & 1.1 & 69 & 70 & - & 6 & 9 & 6 & 94 \\
\hline & neutral & 0.2 & 12 & 45 & 55 & - & - & - & 97 \\
\hline \multirow{2}{*}{$\begin{array}{r}\mathrm{Pt}- \\
\mathrm{Fe}\end{array}$} & alkaline & 19.1 & 100 & 62 & - & 9 & 8 & - & 79 \\
\hline & neutral & 2.8 & 40 & 42 & - & - & - & - & 77 \\
\hline
\end{tabular}

${ }^{a}$ Reaction conditions: initial EG concentration $=0.58 \mathrm{~mol} / \mathrm{L}$, EG:metal ratio $=5657: 1(\mathrm{~mol}: \mathrm{mol}), 70{ }^{\circ} \mathrm{C}, 1$ atm $\mathrm{O}_{2}, 60 \mathrm{std} \mathrm{mL} / \mathrm{min}$, TOF values are based on experimental data at an EG conversion of $5 \%-25 \% .{ }^{b}$ Conversion, selectivity, and carbon balance data are based on values at $12 \mathrm{~h}$, using the formula given in the SI. ${ }^{c} \mathrm{CB}$ data is calculated on the basis of liquid products only.

\section{EXPERIMENTAL SECTION}

Catalyst Synthesis and Characterization. $1 \% \mathrm{Pt} / \mathrm{CeO}_{2}$ and $1 \% \mathrm{Pt}-\mathrm{Fe} / \mathrm{CeO}_{2}$ catalysts were prepared following the method reported previously. ${ }^{17} \mathrm{~N}$-dimethylformamide (DMF) (HPLC grade, $>99.9 \%$ ), cerium oxide nanopowder (particle size $<50 \mathrm{~nm}$, surface area $=30 \mathrm{~m}^{2} / \mathrm{g}$ by BET), and $\mathrm{Pt}(\mathrm{acac})_{2}$ and $\mathrm{Fe}(\mathrm{acac})_{3}(\mathrm{acac}=$ acetylacetonate $)$ were all purchased from Sigma-Aldrich and used without further purification. The molar ratio of $\mathrm{Pt}$ and Fe precursors is (1:1). The sizes of $\mathrm{Pt}$ and $\mathrm{Pt}-\mathrm{Fe}$ nanoparticles are $11.8 \pm 3.8 \mathrm{~nm}$ and $17.3 \pm 4.9$ $\mathrm{nm}$, respectively, as inferred from transmission electron microscopy (TEM) micrographs. ${ }^{17}$

Powder X-ray diffraction (XRD) pattern for the bimetallic $\mathrm{Pt}-\mathrm{Fe}$ catalyst was obtained on a Bruker D8 powder diffractometer with a copper target $(\mathrm{Cu} K \alpha$ radiation) operating at $40 \mathrm{kV}$ and a current of $40 \mathrm{~mA}$. X-ray absorption spectroscopy (XAS) was performed at the SPring-8/BL36XU facility in Japan. Data analysis of extended X-ray absorption fine structure (EXAFS) was performed using the IFEFFIT package, using standard procedures. ${ }^{18}$ The Fe K-edge spectrum of the bimetallic $\mathrm{Pt}-\mathrm{Fe} / \mathrm{CeO}_{2}$ catalyst was measured in fluorescence mode under ambient conditions. The Fe K-edge spectrum of a metallic Fe foil was collected simultaneously in the reference mode for X-ray energy calibration and data analysis.

Oxidation Reaction. The catalytic performance was evaluated in a stirred reactor setup, as described previously (also see Scheme S2 in the Supporting Information (SI)). ${ }^{1}$ In a typical example, an aqueous solution $(25 \mathrm{~mL}, 0.58 \mathrm{~mol} / \mathrm{L})$ of EG (anhydrous, 99.8\%, Sigma-Aldrich), and $0.05 \mathrm{~g}$ catalyst were placed in a $100 \mathrm{~mL}$ three-neck flask and heated to $70{ }^{\circ} \mathrm{C}$ under magnetic stirring. The flask was equipped with an overhead condenser and placed in an oil bath for precise temperature control. $\mathrm{O}_{2}$ was bubbled into the aqueous solution with gas flow rate maintained at $60 \mathrm{std} \mathrm{mL} / \mathrm{min}$. The Pt and $\mathrm{Pt}-\mathrm{Fe}$ catalysts were tested under both neutral $(\mathrm{pH} \sim 7)$ and basic conditions. $\mathrm{NaOH}(1.7 \mathrm{~g})$ was dissolved in the reaction solution prior to the reaction to attain basic conditions $(\mathrm{pH}$ 13.9). Approximately $0.5-1 \mathrm{~mL}$ of reaction solution was sampled from the reactor and neutralized with sulfuric acid for compositional analysis using high-performance liquid chromatography (HPLC) (Shimadzu, Model Shodex SH1011 column) to obtain concentration-time profiles.

Hydrogen peroxide formation during the reaction was detected and quantified by a colorimetric method using the ultraviolet-visible light (UV-vis) spectroscopy (Model Lambda 850 UV-vis Spectrometer, PerkinElmer).$^{19}$ A quantity of 2 $\mathrm{mL}$ of reaction solution was sampled from the reactor and mixed immediately with $2 \mathrm{~mL}$ of diluted $\mathrm{H}_{2} \mathrm{SO}_{4}$ aqueous solution $(1 \mathrm{~mol} / \mathrm{L})$ and $0.2 \mathrm{~mol}$ of $\mathrm{TiO}\left(\mathrm{SO}_{4}\right)$ indicator $(15 \mathrm{wt}$ $\%$ in dilute $\mathrm{H}_{2} \mathrm{SO}_{4}$, purchased from Sigma-Aldrich). A quantity of $30 \mathrm{wt} \% \mathrm{H}_{2} \mathrm{O}_{2}$, purchased from Fisher Scientific, was used to prepare a series of $\mathrm{H}_{2} \mathrm{O}_{2}$ aqueous solutions of known concentrations for calibration purposes. The peak height corresponding to $\mathrm{H}_{2} \mathrm{O}_{2}$ absorbance at $405 \mathrm{~nm}$ is used for quantification purposes. The lower limit of $\mathrm{H}_{2} \mathrm{O}_{2}$ detection by this method is $\sim 0.005 \mathrm{mM}$, as reported previously. ${ }^{19}$

Experimental data on the effects of reaction conditions were collected using a $100 \mathrm{~mL}$ semibatch reactor equipped with precise temperature and pressure control (see Scheme S3 in the SI). The experimental conditions were as follows: $T=70$ ${ }^{\circ} \mathrm{C}$; catalyst loading $=2 \mathrm{~kg} / \mathrm{m}^{3} ; P_{\mathrm{O}_{2}}=10-50 \mathrm{bar}$; initial EG 
concentration $=0.15-0.60 \mathrm{~mol} / \mathrm{L}$ in aqueous solution; $\mathrm{NaOH}: \mathrm{EG}$ molar ratio $=0-4.8$. The absence of heat- and mass-transfer limitations was confirmed by estimating gasliquid, liquid-solid, and intraparticle mass-transfer limitations using the well-known criteria described by Ramachandran and Chaudhari. $^{20}$ Intraparticle heat-transfer limitations were quantified based on the Mears criterion. ${ }^{21}$

\section{RESULTS AND DISCUSSION}

Results of Bimetallic Effect on EG Oxidation. The concentration-time profiles for $\mathrm{Pt}$ and $\mathrm{Pt}-\mathrm{Fe}$ catalysts during EG oxidation at $70{ }^{\circ} \mathrm{C}$ and ambient $\mathrm{O}_{2}$ pressure are shown in Figure 1. Catalytic performance metrics including activity (turnover frequency, TOF), EG conversion, and product selectivity under both neutral and alkaline conditions are presented in Table 1 . The support material $\left(\mathrm{CeO}_{2}\right)$ was also tested but showed no activity for EG oxidation. The base $(\mathrm{NaOH})$ acts as a promoter for both $\mathrm{Pt}$ and $\mathrm{Pt}-\mathrm{Fe}$ catalysts, showing TOF values 5-6 times greater than the values observed under neutral conditions for monometallic Pt. The bimetallic $\mathrm{Pt}-\mathrm{Fe}$ catalyst shows a significantly higher activity, compared to the monometallic Pt catalyst, under both neutral and alkaline conditions. The calculated initial TOF for $\mathrm{Pt}-\mathrm{Fe}$ is $\sim 19.1 \mathrm{~s}^{-1}$, which is more than 17 times greater than that of the Pt catalyst $\left(\right.$ TOF $=1.11 \mathrm{~s}^{-1}$ ) in the presence of a base promoter. As can be seen from Figure 1, EG is entirely converted during $4 \mathrm{~h}$ using the $\mathrm{Pt}-\mathrm{Fe}$ catalyst, while the $\mathrm{Pt}$ catalyst gives much less conversion in the same duration. However, significant carbon deficit in liquid phase products was observed due to overoxidation $\left(\mathrm{CO}_{2}\right.$ formation $)$ when $\mathrm{Pt}-$ $\mathrm{Fe}$ catalyst is used. To confirm the reason for causing the significant carbon deficit, gas chromatography (GC) analysis of $\mathrm{CO}_{2}$ in the gas phase after reaction and titration of carbonate formed in the liquid phase has been performed, and these data are presented in Section 6 of the SI. The results show that there is no $\mathrm{CO}_{2}$ in the gas phase after the reaction. In addition, the formation of carbonate analyzed via a titration method is consistent with the calculated carbonate concentration based on the carbon deficit (due to $\mathrm{CO}_{2}$ formation).

Based on DFT calculations associated with aqueous-phase oxidation of glycerol, Davis and co-workers reported that $\mathrm{O}_{2}$ dissociation on $\mathrm{Au}$ or Pt surface is not facile. ${ }^{19,22,23}$ By using isotope labeling experiments, they proved that $\mathrm{O}_{2}$ was involved in the reaction by taking $\mathrm{H}$ atoms from water or glycerol to form $\mathrm{OOH}$ species, which reacts with deprotonated glycerol to form the glyceric acid, producing $\mathrm{H}_{2} \mathrm{O}_{2}$ as a byproduct. To verify if the EG oxidation on Pt follows a similar mechanism (as shown in Scheme S4 in the SI), we measured possible $\mathrm{H}_{2} \mathrm{O}_{2}$ formation as a byproduct (results shown in Table 2). We found that $\mathrm{H}_{2} \mathrm{O}_{2}$ was indeed formed during EG oxidation on both $\mathrm{Pt}$ and $\mathrm{Pt}-\mathrm{Fe}$ catalysts. It is interesting to see that the

Table 2. Temporal $\mathrm{H}_{2} \mathrm{O}_{2}$ Concentration during EG Oxidation in Alkaline Solution over Pt and Pt-Fe Catalysts

\begin{tabular}{ccc} 
& \multicolumn{2}{c}{$\mathrm{H}_{2} \mathrm{O}_{2}$ Concentration $(\mathrm{mol} / \mathrm{L})$} \\
\cline { 2 - 3 } time (h) & with Pt catalyst & with Pt-Fe catalyst \\
0.5 & $5.0 \times 10^{-4}$ & $2.4 \times 10^{-4}$ \\
1 & $1.3 \times 10^{-3}$ & $2.2 \times 10^{-4}$ \\
2 & $1.5 \times 10^{-3}$ & $8.3 \times 10^{-5}$ \\
4 & $8.3 \times 10^{-4}$ & $6.4 \times 10^{-5}$ \\
12 & $4.2 \times 10^{-4}$ & -
\end{tabular}

$\mathrm{H}_{2} \mathrm{O}_{2}$ concentration on the Pt catalyst first increases then decreases whereas this trend was not observed in the case of $\mathrm{Pt}-\mathrm{Fe}$ catalyst. The formation of $\mathrm{H}_{2} \mathrm{O}_{2}$ on $\mathrm{Pt}-\mathrm{Fe}$ catalyst at the start of the reaction was the strongest. This phenomenon correlates well with the reaction profiles of the two catalysts. A relatively long induction period $(\sim 0-4 \mathrm{~h}$ in Figure $1 \mathrm{a})$ was observed for the Pt catalyst. In contrast, no such induction period was observed for the oxidation using the $\mathrm{Pt}-\mathrm{Fe}$ catalyst. It is also worth mentioning that the $\mathrm{H}_{2} \mathrm{O}_{2}$ formation with the $\mathrm{Pt}-\mathrm{Fe}$ catalyst is less pronounced. The instantaneous $\mathrm{H}_{2} \mathrm{O}_{2}$ concentration in the reaction solution with $\mathrm{Pt}-\mathrm{Fe}$ catalyst is an order of magnitude lower than that observed with the $\mathrm{Pt}$ catalyst. This suggests that the $\mathrm{Pt}-\mathrm{Fe}$ catalyst increases the reaction rate by a different reaction mechanism that does not promote the formation of $\mathrm{OOH}$ species during reaction.

Catalyst Characterization and Structure-Activity Relationship. To interpret the bimetallic effect and draw conclusions based on surface chemistry, we performed detailed characterization studies. In our previous publication, ${ }^{17}$ we have shown that the synthesized bimetallic $\mathrm{Pt}-\mathrm{Fe}$ nanoparticle showed an alloyed structure. To derive more structural information for this bimetallic alloy, XRD analysis was used to characterize the $\mathrm{Pt}-\mathrm{Fe} / \mathrm{CeO}_{2}$ catalyst used in this work. Two crystal structures of $\mathrm{Pt}-\mathrm{Fe}$ alloy are known in the literature: ${ }^{24}$ (1) disordered faced-centered cubic (fcc) (A1 phase, Figure $2 \mathrm{a}$ ) and (2) ordered face-centered tetragonal (fct) phase $\left(\mathrm{L}_{0}\right.$ phase, Figure $\left.2 \mathrm{~b}\right)$. The XRD spectra of $\mathrm{CeO}_{2}-$ supported $\mathrm{Pt}-\mathrm{Fe}$ catalysts of different metal loadings are shown in Figure $2 \mathrm{c}$. The sample with $1 \mathrm{wt} \%$ metal loading did not show any clear diffraction peaks besides the peaks of $\mathrm{CeO}_{2}$, because of the sensitivity limitation of the XRD instrument. At increased metal loadings of 5 or 10 wt $\%$, the characteristic diffraction lines of the $\mathrm{Pt}-\mathrm{Fe}$ alloy at $2 \theta=23.0^{\circ}, 40.4^{\circ}$, and $82.8^{\circ}$ are well-defined, indicating that the $\mathrm{Pt}-\mathrm{Fe}$ catalyst belong to a fcc crystal structure with a calculated lattice constant of $a=0.386 \mathrm{~nm}$ (see Table S2 in the SI). The peaks representing the $\mathrm{Pt}$ crystal or the Fe crystal were not found in the spectra, indicating that our catalyst is highly alloyed. Dominance of the fcc disordered phase occurs in most of the current $\mathrm{Pt}-\mathrm{Fe}$ nanoparticle preparation techniques without thermal treatment. Post-deposition annealing at a temperature of $\sim 600{ }^{\circ} \mathrm{C}$ is usually required to achieve the formation of ordered fct structure of the $\mathrm{Pt}-\mathrm{Fe}$ alloy, according to the phase diagram of the $\mathrm{Pt}-\mathrm{Fe}$ system.

The XPS results shown in our previous publication revealed that the Pt maintains metallic state before or even after oxidation reaction. ${ }^{17}$ However, the oxidation state of $\mathrm{Fe}$ in $\mathrm{Pt}-$ Fe alloy has not been previously reported under liquid-phase oxidation conditions. In this paper, the used $\mathrm{Pt}-\mathrm{Fe}$ catalyst after one 12-h run of EG oxidation was investigated with the EXAFS technique to discern more information about the PtFe alloy structure. As shown in Figure 3a, the Pt-Fe catalyst's absorption edge curve is more consistent with that of $\mathrm{Fe}$ foil, instead of the $\mathrm{Fe}_{2} \mathrm{O}_{3}$ standard sample. Besides, no $\mathrm{Fe}-\mathrm{O}$ coordination was found in the r-space figure, as shown in Figures $3 \mathrm{~b}$ and $3 \mathrm{c}$. In other words, the Fe element in the $\mathrm{Pt}-$ Fe alloy remains in a reduced state $\left(\mathrm{Fe}^{0}\right)$.

Given that Fe metallic nanoparticle can be easily oxidized in an $\mathrm{O}_{2}$ and moisture-rich environment, the above finding seems unexpected. In the EXAFS study of $\mathrm{Pt}-\mathrm{Fe} /$ zeolite by Kotobuki, even after hydrogen reduction treatment, Fe center atom was coordinated by not only $\mathrm{Pt}$ and Fe but also by O. ${ }^{25}$ However, researchers also found that noble metals such as $\mathrm{Pt}$ 

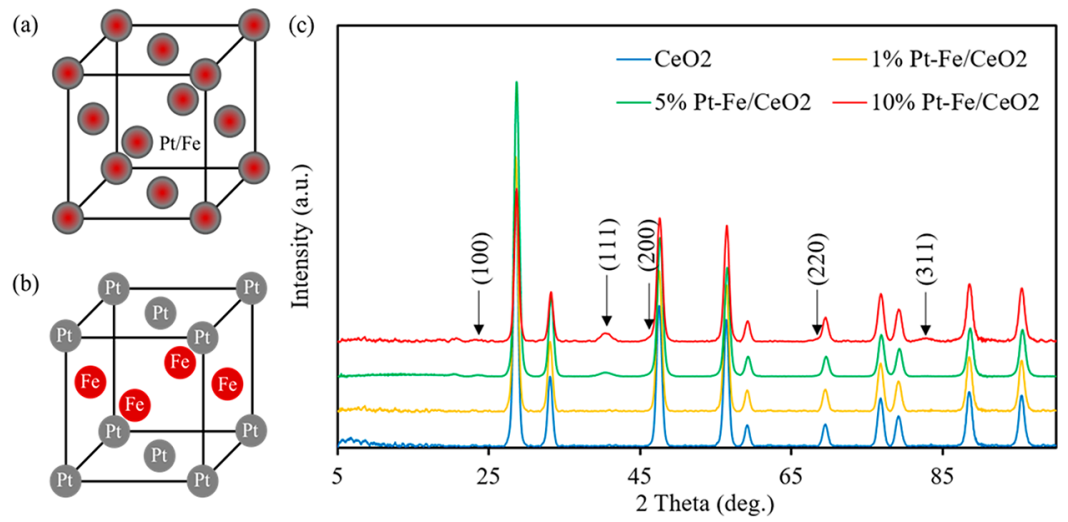

Figure 2. Schematic of the Pt-Fe crystal structure of the (a) disordered fcc and (b) ordered fct phases. (c) X-ray diffraction pattern of the ceriumoxide-supported $\mathrm{Pt}-\mathrm{Fe}$ catalyst.
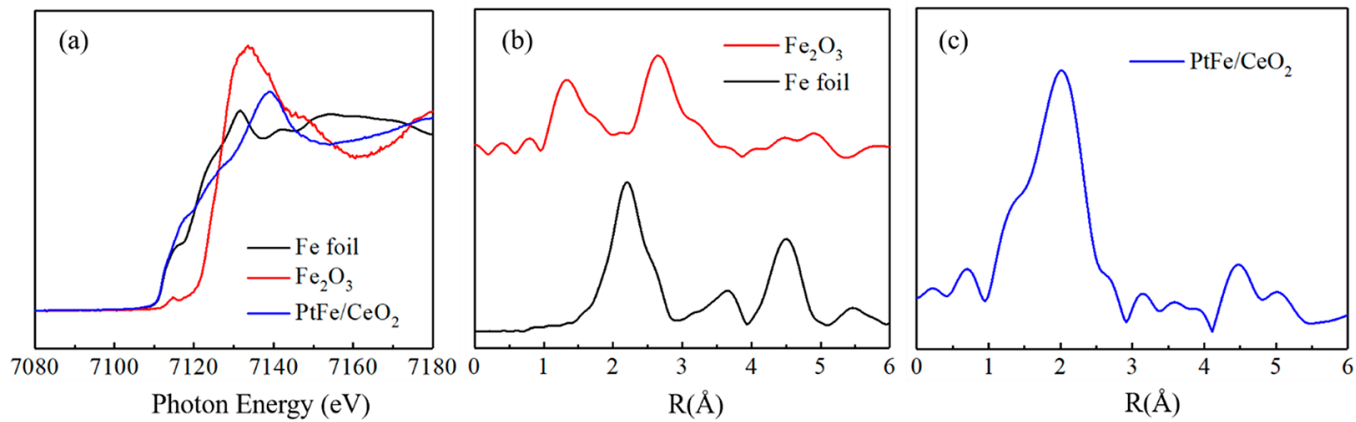

Figure 3. (a) Fe K-edge XAS spectra of Fe foil, ferric oxide, and the Pt-Fe catalyst; (b) Fourier transformation of EXAFS for Fe foil and ferric oxide; and (c) Fourier-transformation of EXAFS for the Pt-Fe catalyst.

can enhance the reduction of iron by intimately contacting with them in the supported bimetallic catalysts, ${ }^{26}$ because of the strong hybridization of Pt $5 \mathrm{~d}$ bands with highly polarized $\mathrm{Fe} 3 \mathrm{~d}$ bands. It has been found that the reduced state of $\mathrm{Fe}$ is largely dependent on the degree of its alloying with Pt. Although pure Fe surfaces are known to be highly reactive with $\mathrm{O}_{2}$ such that the surface metallic $\mathrm{Fe}$ can be oxidized to form $\mathrm{FeO}$, the surface-alloyed $\mathrm{Fe}$ can remain stable, even when exposed to $\mathrm{O}_{2}$-rich reaction conditions. In an $\mathrm{O}_{2} / \mathrm{CO}$ adsorption study combined with XPS characterization by $\mathrm{Xu}$ et al., ${ }^{27}$ the $\mathrm{Pt}-\mathrm{Fe}$ alloy after adsorption of $\mathrm{O}_{2}$ displayed similar $\mathrm{O} 1 \mathrm{~s}$ intensity, compared to that of the $\mathrm{Pt}$ nanoparticle. Also, the $\mathrm{Fe} 2 \mathrm{p}^{3 / 2}$ positive shift is found to be almost negligible ( 0.2 $\mathrm{eV}$ ), indicating that $\mathrm{Fe}$ in a highly alloyed structure was resistant to oxidation and still highly active to $\mathrm{CO}$ oxidation. ${ }^{27}$ Considering the highly alloyed structure of our $\mathrm{Pt}-\mathrm{Fe}$ catalyst, as observed from XRD spectra, we conclude that the assignment of the $\mathrm{Fe}^{0}$ state is reasonable.

Pt alloys involving $3 \mathrm{~d}$ metals are usually found to be better catalysts than $\mathrm{Pt}$, because the $\mathrm{d}$ band of the $\mathrm{Pt}$ atoms on the surface of these alloys are modified. ${ }^{28}$ Based on the d-band theory, catalyst activity is dependent on the strength of adsorbate-metal bond interaction to a large extent, which, in turn, is dependent on the position of the metal d-states, relative to the Fermi level. ${ }^{29}$ In our study, the crystalline lattice spacing reduction (lattice constant of $\mathrm{Pt}=0.392 \mathrm{~nm}$ ) is decreased to $0.386 \mathrm{~nm}$ in the Pt-Fe alloy, see Table S1 in the SI for details) can result in the downward shifting of the d-band center, weakening the bonding between Pt and adsorbent (EG) and therefore tuning the catalytic performance.
Because of the difference in electronegativity of $\mathrm{Pt}$ and $\mathrm{Fe}$, electron transfer from $\mathrm{Fe}$ to $\mathrm{Pt}$ occurs upon the formation of $\mathrm{Pt}-\mathrm{Fe}$ bonding in the alloyed structure nanocrystal. ${ }^{27}$ This electron transfer from $\mathrm{Fe}$ to $\mathrm{Pt}$ on the surface can modify the adsorption energy of EG or $\mathrm{O}_{2}$ on the Pt metal surface. In addition, DFT calculations show that the existence of alloyed $\mathrm{Fe}$ atoms can improve $\mathrm{O}_{2}$ dissociation. ${ }^{30}$ It has been found that the reaction energy barrier of $\mathrm{O}_{2}$ dissociation on atomically dispersed $\mathrm{Fe}$ sites in the $\mathrm{Pt}-\mathrm{Fe}$ alloy is very low $(\sim 0.32 \mathrm{eV})$, and the $\mathrm{O}$ adsorption energy is also much lower $(-1.63 \mathrm{eV})$ than the adsorption energy of other Fe surfaces. ${ }^{30}$ Therefore, the phenomenon of less-pronounced $\mathrm{H}_{2} \mathrm{O}_{2}$ formation with $\mathrm{Pt}-$ Fe catalyst is explained as follows. Part of the $\mathrm{O}_{2}$ does not react with water to generate $\mathrm{OOH}$ species like it does on the $\mathrm{Pt}$ surface. However, the $\mathrm{O}_{2}$ dissociates on the $\mathrm{Pt}-\mathrm{Fe}$ surface and then reacts with the adsorbed EG to form the glycolic acid. Oxidation via this pathway cannot form $\mathrm{H}_{2} \mathrm{O}_{2}$ as a byproduct. To verify this proposed mechanism, we performed the following parametric effect studies.

Effect of Reaction Conditions. The $\mathrm{O}_{2}$ pressure effect on the initial reaction rate was studied with monometallic $\mathrm{Pt}$ catalyst for both neutral and alkaline conditions while keeping the other reaction parameters constant. The concentrationtime profiles are shown as Figures $4 \mathrm{a}$ and $4 \mathrm{c}$. The initial reaction rate for EG conversion at various $\mathrm{O}_{2}$ pressures is shown in Figures $4 \mathrm{~b}$ and $4 \mathrm{~d}$. While the EG oxidation rate does not change with $\mathrm{O}_{2}$ pressure under neutral conditions, it shows a linear dependence with $\mathrm{O}_{2}$ pressure under alkaline conditions. In other words, the reaction order, with respect to $\mathrm{O}_{2}$ pressure, is increased from zero to one by the base promotion effect. It was reported that $\mathrm{Na}^{+}$attached on the 

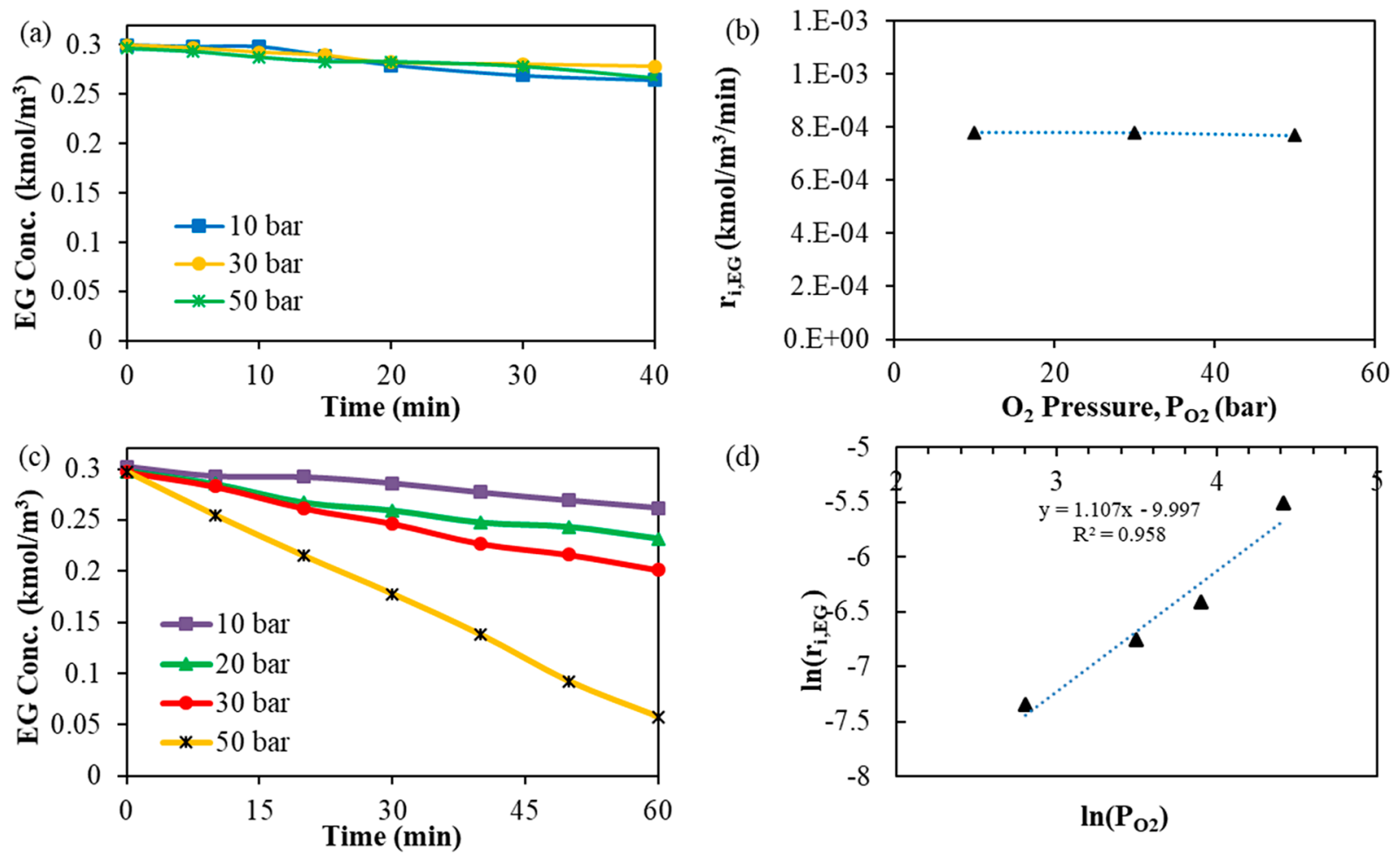

(d)

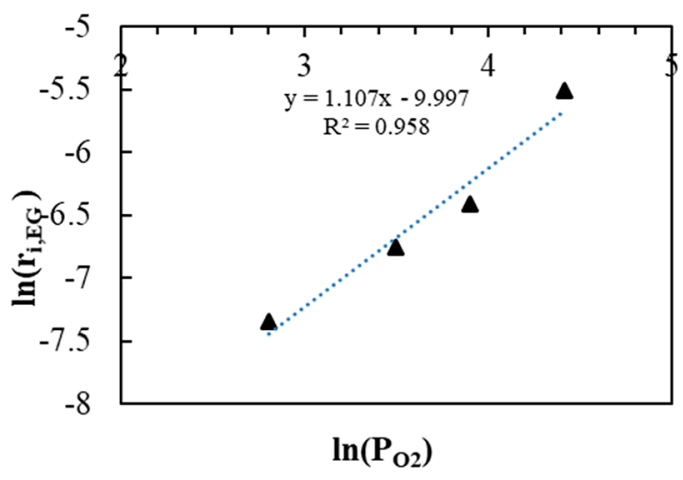

Figure 4. Oxygen pressure effect on EG oxidation with Pt catalyst: (a) EG concentration-time (C-t) profiles under neutral conditions; (b) $\mathrm{O}_{2}$ pressure effect on initial reaction rate under neutral conditions; (c) EG concentration-time $(C-t)$ profiles under alkaline conditions; $(d) \mathrm{O}_{2}$ pressure effect on initial reaction rate under alkaline conditions. Reaction conditions: initial EG concentration $=0.295 \mathrm{kmol} / \mathrm{m}^{3}, 70{ }^{\circ} \mathrm{C}, P_{\mathrm{O}_{2}}=30$ bar, initial $\mathrm{NaOH}$ concentration $=1.458 \mathrm{kmol} / \mathrm{m}^{3}$ under alkaline conditions; no $\mathrm{NaOH}$ was added under neutral conditions, catalyst loading (Pt/ $\left.\mathrm{CeO}_{2}\right)=2 \mathrm{~kg} / \mathrm{m}^{3}$; the initial reaction rate $\left(r_{\mathrm{i}, \mathrm{EG}}\right)$ is calculated based on the data of EG conversion $(\leq 15 \%)$.

metal surface can promote the adsorption of electron acceptors $\left(\mathrm{O}_{2}\right)$ while inhibiting the adsorption of the electron donor (EG in this study). ${ }^{31,32}$ By moderating the relative adsorption strengths, the alkali metals allow more $\mathrm{O}_{2}$ to be adsorbed on the active sites, leading to an acceleration of the reaction. In addition, according to the proposed reaction mechanism on the $\mathrm{Pt}$ catalyst, $\mathrm{O}_{2}$ is a suitable electron acceptor ${ }^{22}$ that removes $\mathrm{OH}^{-}$electrons on the metal surface to provide additional $\mathrm{OH}^{*}$ species (see eq vii in Scheme S4 in the SI). The $\mathrm{OH}^{*}$ subsequently reacts with deprotonated EG species $\left(\mathrm{HOCH}_{2} \mathrm{CO}^{*}\right)$ to form the glycolic acid. However, $\mathrm{OH}^{*}$ cannot be provided easily from deprotonation of $\mathrm{H}_{2} \mathrm{O}$ under neutral conditions, and, hence, the reaction proceeds slowly.

Effect of initial EG concentration on the EG reaction rate with Pt catalyst is also dramatically different for the neutral and alkaline conditions (Figure 5). Under neutral conditions, the reaction rate increases very rapidly with an increase in initial EG concentration from $0.15 \mathrm{kmol} / \mathrm{m}^{3}$ to $0.6 \mathrm{kmol} / \mathrm{m}^{3}$ but remains constant at EG concentrations greater than $0.6 \mathrm{kmol} /$ $\mathrm{m}^{3}$. In contrast, a strong inhibition effect was observed for the EG oxidation rate under alkaline conditions, with respect to EG concentration. The EG oxidation rates continuously decrease with an increase in initial EG concentration in the $0.15-1.2 \mathrm{kmol} / \mathrm{m}^{3}$ range, suggesting strong EG adsorption on the catalyst surface, when compared to $\mathrm{O}_{2}$. This inhibition effect may also be observed from the results in Figure 1. A "slow" oxidation period exists during the first $4 \mathrm{~h}$ of reaction, following which the reaction rate accelerates due to the alleviation of rate inhibition upon EG consumption.

Similar effects of $\mathrm{O}_{2}$ pressure and initial EG concentration dependence on the reaction rates for the $\mathrm{Pt}-\mathrm{Fe}$ bimetallic
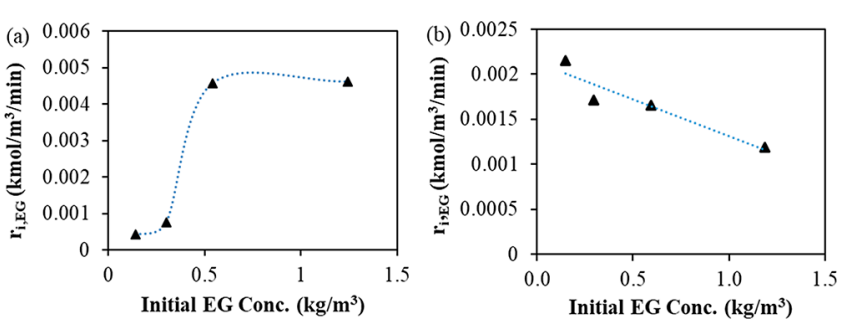

Figure 5. Initial EG concentration effect of EG oxidation on Pt catalyst: (a) neutral conditions (no base added) and (b) alkaline conditions (initial $\mathrm{NaOH}$ concentration $=1.458 \mathrm{kmol} / \mathrm{m}^{3}$ ). Reaction conditions: initial EG concentration $=0.295 \mathrm{kmol} / \mathrm{m}^{3}, 70{ }^{\circ} \mathrm{C}, P_{\mathrm{O}_{2}}=$ 30 bar, catalyst loading $\left(\mathrm{Pt} / \mathrm{CeO}_{2}\right)=2 \mathrm{~kg} / \mathrm{m}^{3}$, initial reaction rate $\left(r_{\mathrm{i}, \mathrm{EG}}\right)$ is calculated based on the data of EG conversion $\leq 15 \%$.

catalyst are shown in Figure 6. Interestingly, the reaction order, with respect to $\mathrm{O}_{2}$, is markedly different for the bimetallic catalyst, compared to the monometallic Pt catalyst. Under neutral conditions, the reaction rate increases linearly with the $\mathrm{O}_{2}$ pressure, yielding a reaction order of $\sim 1$, as observed from the $\ln \left(r_{\mathrm{i}, \mathrm{EG}}\right)$ and $\ln \left(P_{\mathrm{O}_{2}}\right)$ plot (Figure 6a). This confirms that $\mathrm{O}_{2}$ is involved in the rate-determining step for EG oxidation in the case of the $\mathrm{Pt}-\mathrm{Fe}$ catalyst. Furthermore, the $\mathrm{O}_{2}$ reaction order was increased to $\sim 2$ under alkaline conditions, as observed from Figure $6 \mathrm{~b}$. The effect of initial EG concentration on the $\mathrm{Pt}-\mathrm{Fe}$ catalyst is similar to that observed with the $\mathrm{Pt}$ catalyst. A mixed-order dependence (first order at low EG concentration and zero order at higher EG concentrations) was observed under neutral conditions, while EG inhibition was observed under alkaline conditions. Thus, the adsorption 

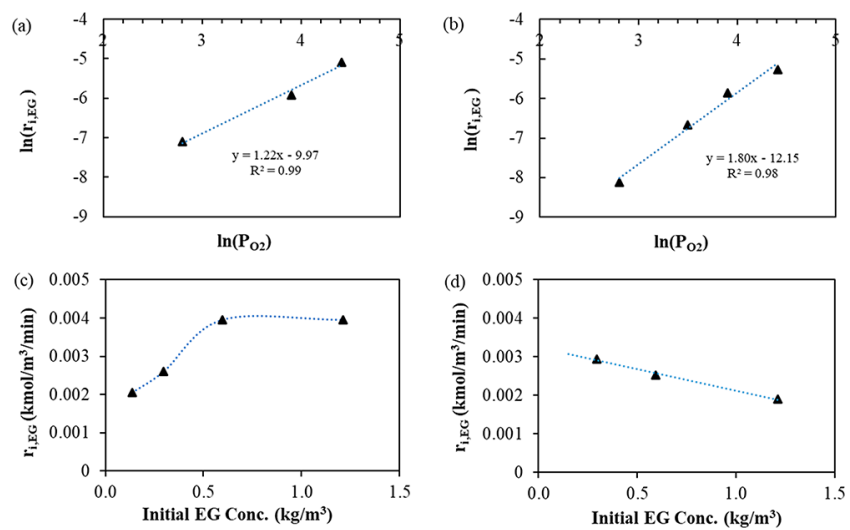

Figure 6. Oxygen pressure effect on EG oxidation with $\mathrm{Pt}-\mathrm{Fe}$ catalyst: (a) EG concentration-time profiles under neutral conditions; (b) $\mathrm{O}_{2}$ pressure effect on initial reaction rate under neutral conditions; (c) EG concentration-time profiles under alkaline conditions; and (d) $\mathrm{O}_{2}$ pressure effect on initial reaction rate under alkaline conditions. Reaction conditions: initial EG concentration = $0.295 \mathrm{kmol} / \mathrm{m}^{3}, 70{ }^{\circ} \mathrm{C}, P_{\mathrm{O}_{2}}=30 \mathrm{bar}$, initial $\mathrm{NaOH}$ concentration = $1.458 \mathrm{kmol} / \mathrm{m}^{3}$ under alkaline conditions; no $\mathrm{NaOH}$ was added under neutral conditions, catalyst loading $\left(\mathrm{Pt}-\mathrm{Fe} / \mathrm{CeO}_{2}\right)=2 \mathrm{~kg} / \mathrm{m}^{3}$, initial reaction rate $\left(r_{\mathrm{i}, \mathrm{EG}}\right)$ is calculated based on the data of $\mathrm{EG}$ conversion $\leq 15 \%$.

characteristics of EG on the bimetallic catalyst do not appear to have changed significantly.

The observed bimetallic effect is caused by the easier $\mathrm{O}_{2}$ dissociation on the catalyst surface due to alloy structure, as explained earlier. In addition, the $\mathrm{O}_{2}$ adsorption on the surface is likely enhanced by the $\mathrm{Fe}$ species in the catalyst. Kotobuki et al. reported $\mathrm{CO}, \mathrm{H}_{2}$, and $\mathrm{O}_{2}$ chemisorption measurements of mordenite-supported $\mathrm{Pt}, \mathrm{Fe}$, and $\mathrm{Pt}-\mathrm{Fe}$ catalysts, demonstrating that $\mathrm{Pt}$ sites act as adsorption sites for only $\mathrm{CO}$ and $\mathrm{H}_{2}$, while $\mathrm{Fe}$ or $\mathrm{FeO}$ sites are primarily responsible for $\mathrm{O}_{2}$ adsorption. ${ }^{33}$ Consistent with these observations, a dual site mechanism was proposed in their work to explain the effect of adding $\mathrm{Fe}$ to the catalytic system for PROX (preferential oxidation of $\mathrm{CO}$ in $\mathrm{H}_{2}$ ) reaction. Pt acts as a $\mathrm{CO}$ adsorption site, while $\mathrm{Fe}$ is responsible for the $\mathrm{O}_{2}$ dissociative-adsorption site. Herein, we invoke a similar reaction mechanism for EG oxidation over the $\mathrm{Pt}-\mathrm{Fe}$ catalyst.

We also investigated the effect of base for both $\mathrm{Pt}$ and $\mathrm{Pt}-\mathrm{Fe}$ catalysts while keeping other reaction parameters constant (see Figure 7). Contrary to our expectations, the base $(\mathrm{NaOH})$ not only acts as a promoter, as previously claimed in the literature, ${ }^{19}$ but is actually an inhibitor at sufficiently high concentrations. This phenomenon was not previously reported for the oxidation of polyols or carbohydrates, most likely because previous studies were typically conducted at fixed $\mathrm{NaOH}$ concentrations. The trend of reaction rate versus base amount was observed to be similar for the $\mathrm{Pt}$ and $\mathrm{Pt}-\mathrm{Fe}$ catalysts. However, the promotion effect of base under optimum conditions is more significant when bimetallic catalyst is used, which implies a stronger synergistic effect between the bimetallic catalyst and the base.

Not only does the reaction rate change with the amount of base, the product selectivity is also significantly influenced (see Table 3). When no base is used, glycolaldehyde is the main product from EG oxidation over the Pt catalyst (selectivity of $\sim 69.4 \%$ ). At progressively higher base concentrations, the glycolaldehyde selectivity gradually decreases with more

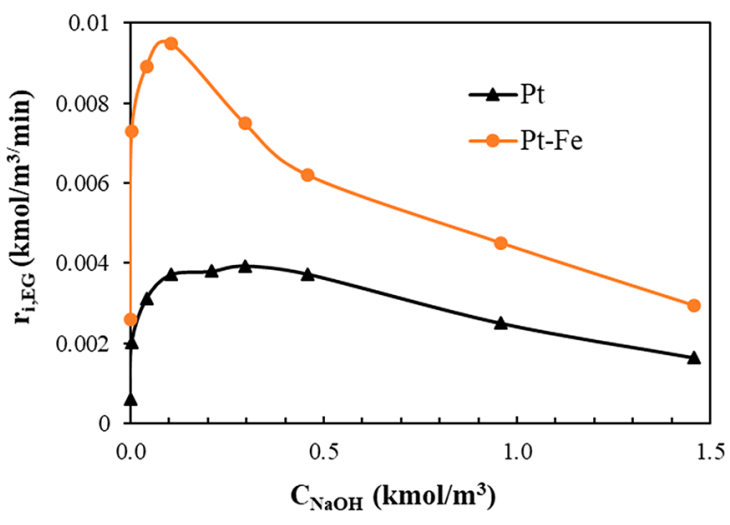

Figure 7. Base effect on initial reaction rate for EG oxidation with the $\mathrm{Pt}$ catalyst. Reaction conditions: initial EG concentration $=0.295$ $\mathrm{kmol} / \mathrm{m}^{3}, 70{ }^{\circ} \mathrm{C}, P_{\mathrm{O}_{2}}=30$ bar, and catalyst loading $\left(\mathrm{Pt} / \mathrm{CeO}_{2}\right)=2$ $\mathrm{kg} / \mathrm{m}^{3}$; the initial reaction rate $\left(r_{\mathrm{i}, \mathrm{EG}}\right)$ is calculated based on the data of EG conversion $\leq 15 \%$.

Table 3. Base Effect on Product Selectivity for Pt Catalyst

\begin{tabular}{cccccc} 
& & \multicolumn{3}{c}{ Selectivity, S (\%) } \\
\cline { 3 - 5 } $\begin{array}{c}C_{\mathrm{NaOH}} \\
\left(\mathrm{kmol} / \mathrm{m}^{3}\right)\end{array}$ & $\begin{array}{c}\text { conversion } \\
\text { \%, EG }\end{array}$ & glycolaldehyde & $\begin{array}{c}\text { glycolic } \\
\text { acid }\end{array}$ & $\begin{array}{c}\text { formic } \\
\text { acid }\end{array}$ & CB \\
0 & 7.1 & 69.4 & 30.6 & - & 1.00 \\
0.004 & 10.8 & 48.2 & 28.1 & - & 0.97 \\
0.042 & 26.7 & 22.2 & 29.7 & - & 0.87 \\
0.104 & 39.0 & 8.3 & 38.8 & - & 0.79 \\
0.212 & 51.0 & 2.5 & 55.0 & - & 0.79 \\
0.296 & 54.4 & 2.7 & 46.7 & 3.9 & 0.74 \\
0.458 & 49.0 & - & 70.2 & 2.6 & 0.87 \\
0.958 & 33.7 & - & 72.3 & 2.3 & 0.91 \\
1.458 & 23.5 & - & 73.3 & 1.7 & 0.94 \\
\hline
\end{tabular}

glycolic acid formation, because of the increased oxidation rate. When the reaction rate is close to its maximum at optimum $\mathrm{NaOH}$ concentration, more carbon balance deficit (based on liquid phase product analysis) was observed, which is attributed to $\mathrm{CO}_{2} / \mathrm{CO}_{3}{ }^{2-}$ formation, as a result of $\mathrm{C}-\mathrm{C}$ cleavage (see Section 7 in the SI). Further increases in the base amount result in less $\mathrm{CO}_{2}$ formation, higher glycolic acid selectivity, and more formic acid as a byproduct. The formation of formic acid was not observed under neutral conditions or lower base concentrations. This phenomenon can be explained by the reaction mechanism demonstrated in Scheme S5 in the SI. When excess $\mathrm{NaOH}$ is used, $-\mathrm{OH}$ from the base occupies the active site that creates steric hindrance to deter $\mathrm{CO}_{2}$ formation from $\mathrm{C}-\mathrm{C}$ cleavage and also decreases the oxidation rate, because of its competitive adsorption with the $-\mathrm{OH}$ groups from the EG.

In addition to $\mathrm{NaOH}$, some "mild" bases were also examined for potential promotional effect in EG oxidation. The concentration-time profiles of EG and the main byproducts are shown in Figure 8 for these experiments. Compared to the case of no base addition, $\mathrm{NaHCO}_{3}$ or $\mathrm{Na}_{2} \mathrm{CO}_{3}$ also accelerate the oxidation reaction initially but only for a short duration. After $\sim 20 \mathrm{~min}$, the reaction rate slows rapidly and almost stops. Therefore, a poisoning effect is caused by the introduction of $\mathrm{HCO}_{3}{ }^{-}$and $\mathrm{CO}_{3}{ }^{2-}$ ions in this reaction system. This explains the "deactivation period" in Figure $1 \mathrm{~b}$ (4-12 h) when no further oxidation can be observed. The poisoning effect of $\mathrm{CO}_{3}{ }^{2-}$ species is attributed to the $\mathrm{CO}_{2}$ 

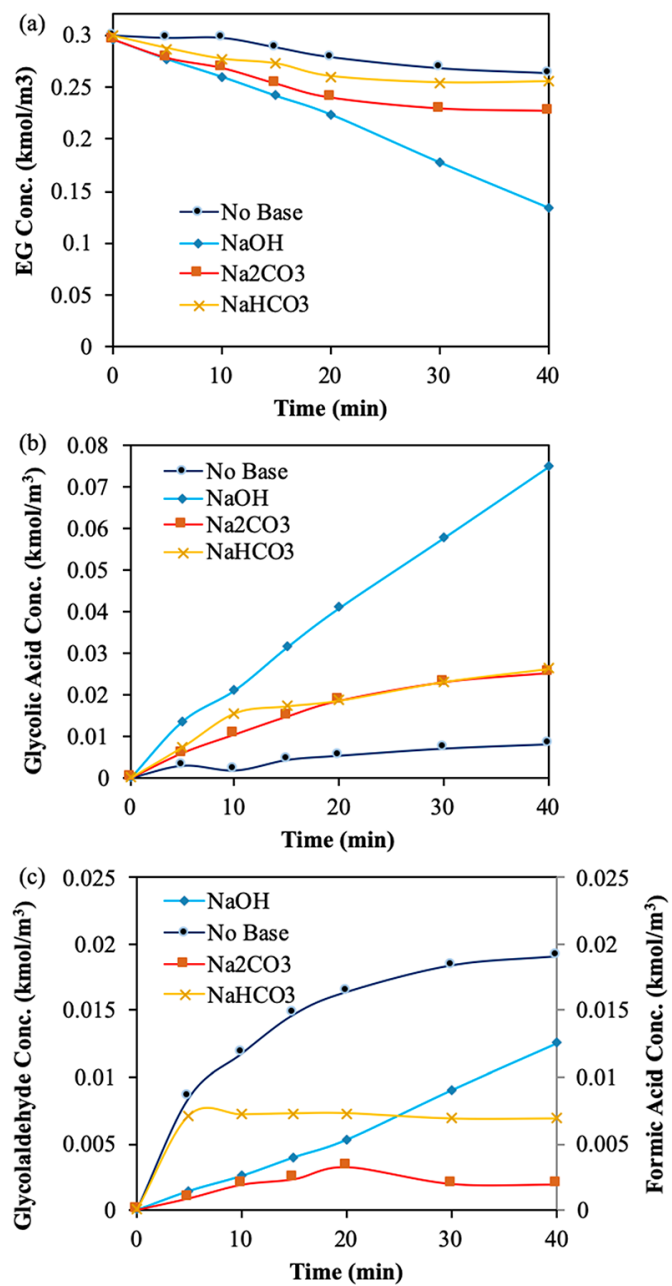

Figure 8. Concentration-time profiles of EG oxidation using different bases with the Pt catalyst: (a) EG, (b) glycolic acid, and (c) glycolaldehyde. Reaction conditions: initial EG concentration = $0.295 \mathrm{kmol} / \mathrm{m}^{3}$, base-to-EG molar ratio $=1: 1,70{ }^{\circ} \mathrm{C}, P_{\mathrm{O}_{2}}=30 \mathrm{bar}$, catalyst loading $\left(\mathrm{Pt} / \mathrm{CeO}_{2}\right)=2 \mathrm{~kg} / \mathrm{m}^{3}$.

produced from the $\mathrm{C}-\mathrm{C}$ cleavage of EG that dissolves in the alkaline water solution. The product distribution patterns with $\mathrm{NaHCO}_{3}$ and $\mathrm{Na}_{2} \mathrm{CO}_{3}$ are similar to that observed under neutral conditions: glycolaldehyde and glycolic acid are the main products with no formic acid detected.

\section{CONCLUSIONS}

Investigations of the aqueous phase oxidation of EG on monometallic $\mathrm{Pt}$ and bimetallic $\mathrm{Pt}-\mathrm{Fe}$ catalyst revealed that the initial turnover frequency (TOF) on the $\mathrm{Pt}-\mathrm{Fe}$ catalyst $\left(19.1 \mathrm{~s}^{-1}\right)$ is $\sim 17$ times greater than that observed on the $\mathrm{Pt}$ catalyst $\left(\mathrm{TOF}=1.11 \mathrm{~s}^{-1}\right)$ in the presence of a base promoter at $70{ }^{\circ} \mathrm{C}$ and an ambient pressure of $\mathrm{O}_{2} .100 \%$ conversion of EG and $62 \%$ glycolic selectivity was obtained at the end of $4 \mathrm{~h}$ of reaction. Unlike the Pt catalyst, the alloyed Pt-Fe structure enables efficient electron transfer from $\mathrm{Fe}$ to $\mathrm{Pt}$ that favors dissociative $\mathrm{O}_{2}$ adsorption on the catalyst surface and its participation in the EG oxidation reaction. This conclusion is supported by the observed differences in the $\mathrm{O}_{2}$ orders on the two catalysts. While the $\mathrm{NaOH}$ base promotes EG oxidation on both $\mathrm{Pt}$ and bimetallic $\mathrm{Pt}-\mathrm{Fe}$ catalysts at lower concentrations, it inhibits the EG oxidation rates at sufficiently higher concentrations. Furthermore, the amount of base also influences the product selectivity, favoring glycolic acid at higher $\mathrm{NaOH}$ concentrations. Under neutral conditions (i.e., without base addition), the EG oxidation rate displays a mixedorder dependence on EG concentration, increasing linearly at low EG concentrations and becoming zero order at higher base concentrations. In the presence of a base, however, the $\mathrm{O}_{2}$ and $\mathrm{OH}$ species also compete for active sites, resulting in the observed rate inhibition and changes in product selectivity.

\section{ASSOCIATED CONTENT}

Supporting Information

The Supporting Information is available free of charge on the ACS Publications website at DOI: 10.1021/acs.iecr.9b03419.

Reaction scheme and experimental set-ups; mechanism of EG oxidation on Pt catalyst; mechanism of base effect on product distribution; XRD calculations; formula of conversion, selectivity and activity calculations; recycling study of Pt-Fe Catalyst; GC determination of $\mathrm{CO}_{2}$ in gas phase and titration determination of carbonate in liquid phase; EG oxidation results of $\mathrm{Fe} / \mathrm{CeO}_{2}$ catalyst on EG oxidation; and $\mathrm{Pt} 4 \mathrm{f}$ XPS of the Pt-Fe catalyst (PDF)

\section{AUTHOR INFORMATION}

\section{Corresponding Author \\ *E-mail: rvc1948@ku.edu. ORCID ${ }^{\circ}$}

Bala Subramaniam: 0000-0001-5361-1954

Raghunath V. Chaudhari: 0000-0002-1972-1620

Author Contributions

$\S_{\text {These authors contributed equally. }}$

Funding

The authors gratefully acknowledge support for this work from a grant from the joint National Science Foundation and Environmental Protection Agency Program Networks for Sustainable Material Synthesis and Design (No. CHE 1339661).

\section{Notes}

The authors declare no competing financial interest.

\section{ACKNOWLEDGMENTS}

The authors thank Dr. Franklin Tao's group at the University of Kansas (KU) for performing the EXAFS and XPS experiments; Dr. Victor Day at KU for performing the XRD experiment; and, Dr. Edward Peltier at KU for carbonate titration analysis and calculations. In addition, we also acknowledge the help from Mohamed Mohamed and Kristofer Ho on the experiments of alkaline promotion effect using PtFe catalyst.

\section{REFERENCES}

(1) Jin, X.; Zeng, C.; Yan, W.; Zhao, M.; Bobba, P.; Shi, H.; Thapa, P. S.; Subramaniam, B.; Chaudhari, R. V. Lattice distortion induced electronic coupling results in exceptional enhancement in the activity of bimetallic PtMn nanocatalysts. Appl. Catal., A 2017, 534, 46-57.

(2) Shi, H.; Thapa, P. S.; Subramaniam, B.; Chaudhari, R. V. Oxidation of Glucose using Mono and Bimetallic Catalysts in Base Free Conditions. Org. Process Res. Dev. 2018, 22, 1653-1662.

(3) Jin, X.; Fang, T.; Wang, J.; Liu, M.; Pan, S.; Subramaniam, B.; Shen, J.; Yang, C.; Chaudhari, R. V. Nanostructured Metal Catalysts for Selective Hydrogenation and Oxidation of Cellulosic Biomass to Chemicals. Chem. Rec. 2019, 19, 1952. 
(4) Katryniok, B.; Kimura, H.; Skrzyńska, E.; Girardon, J.-S.; Fongarland, P.; Capron, M.; Ducoulombier, R.; Mimura, N.; Paul, S.; Dumeignil, F. Selective catalytic oxidation of glycerol: perspectives for high value chemicals. Green Chem. 2011, 13, 1960-1979.

(5) Sun, J.; Liu, H. Selective hydrogenolysis of biomass-derived xylitol to ethylene glycol and propylene glycol on supported $\mathrm{Ru}$ catalysts. Green Chem. 2011, 13, 135-142.

(6) Shmotin, V.; Knyazev, A.; Titkov, A.; Salanov, A.; Vodyankina, O.; Kurina, L. Effect of iodine-containing promoter on the catalytic activity of silver in the course of ethylene glycol oxidation. Russ. J. Appl. Chem. 2006, 79, 1458-1462.

(7) Mamontov, G. V.; Magaev, O.; Knyazev, A.; Vodyankina, O. Influence of phosphate addition on activity of $\mathrm{Ag}$ and $\mathrm{Cu}$ catalysts for partial oxidation of alcohols. Catal. Today 2013, 203, 122-126.

(8) Vodyankina, O. V.; Blokhina, A.; Kurzina, I. A.; Sobolev, V.; Koltunov, K. Y.; Chukhlomina, L.; Dvilis, E. S. Selective oxidation of alcohols over Ag-containing Si3N4 catalysts. Catal. Today 2013, 203, 127-132.

(9) Berndt, H.; Pitsch, I.; Evert, S.; Struve, K.; Pohl, M.-M.; Radnik, J.; Martin, A. Oxygen adsorption on $\mathrm{Au} / \mathrm{Al}_{2} \mathrm{O}_{3}$ catalysts and relation to the catalytic oxidation of ethylene glycol to glycolic acid. Appl. Catal., A 2003, 244, 169-179.

(10) Case, J. M. Gold catalysts prepared by ion exchange for use in ethylene glycol oxidation: An exploratory study. Thesis Dissertation, University of Cape Town, 2009.

(11) Griffin, M. B.; Rodriguez, A. A.; Montemore, M. M.; Monnier, J. R.; Williams, C. T.; Medlin, J. W. The selective oxidation of ethylene glycol and 1,2-propanediol on $\mathrm{Au}, \mathrm{Pd}$, and $\mathrm{Au}-\mathrm{Pd}$ bimetallic catalysts. J. Catal. 2013, 307, 111-120.

(12) Van Haasterecht, T.; Van Deelen, T.; De Jong, K.; Bitter, J. Transformations of polyols to organic acids and hydrogen in aqueous alkaline media. Catal. Sci. Technol. 2014, 4, 2353-2366.

(13) Khan, M. I. A.; Miwa, Y.; Morita, S.; Okada, J. Liquid-phase Oxidation of Ethylene Glycol on a Pt/C Catalyst. II. Kinetic Studies. Chem. Pharm. Bull. 1983, 31, 1827-1832.

(14) Mitsui-Chemicals. Jpn. Patent No. JP 3748588B, 1995.

(15) Nie, L.; Mei, D.; Xiong, H.; Peng, B.; Ren, Z.; Hernandez, X. I. P.; DeLaRiva, A.; Wang, M.; Engelhard, M. H.; Kovarik, L.; Datye, A. $\mathrm{K}$; W Wang, Y. Activation of surface lattice oxygen in single-atom Pt/ $\mathrm{CeO}_{2}$ for low-temperature $\mathrm{CO}$ oxidation. Science 2017, 358, 14191423.

(16) Trovarelli, A. Catalytic properties of ceria and $\mathrm{CeO}_{2}$-containing materials. Catal. Rev.: Sci. Eng. 1996, 38, 439-520.

(17) Jin, X.; Zhao, M.; Yan, W.; Zeng, C.; Bobba, P.; Thapa, P. S.; Subramaniam, B.; Chaudhari, R. V. Anisotropic growth of PtFe nanoclusters induced by lattice-mismatch: Efficient catalysts for oxidation of biopolyols to carboxylic acid derivatives. J. Catal. 2016, 337, 272-283.

(18) Ravel, B.; Newville, M. ATHENA, ARTEMIS, HEPHAESTUS: data analysis for X-ray absorption spectroscopy using IFEFFIT. J. Synchrotron Radiat. 2005, 12, 537-541.

(19) Ketchie, W. C.; Murayama, M.; Davis, R. J. Promotional effect of hydroxyl on the aqueous phase oxidation of carbon monoxide and glycerol over supported Au catalysts. Top. Catal. 2007, 44, 307-317.

(20) Ramachandran, P.; Chaudhari, R. Three-Phase Catalytic Reactors, Vol. 2; Gordon \& Breach Science Publishers, 1983.

(21) Mears, D. E. Tests for transport limitations in experimental catalytic reactors. Ind. Eng. Chem. Process Des. Dev. 1971, 10, 541547.

(22) Ide, M. S.; Davis, R. J. The important role of hydroxyl on oxidation catalysis by gold nanoparticles. Acc. Chem. Res. 2014, 47, 825-833.

(23) Zope, B. N.; Hibbitts, D. D.; Neurock, M.; Davis, R. J. Reactivity of the gold/water interface during selective oxidation catalysis. Science 2010, 330, 74-78.

(24) Wang, J. P. FePt magnetic nanoparticles and their assembly for future magnetic media. Proc. IEEE 2008, 96, 1847-1863.

(25) Kotobuki, M.; Shido, T.; Tada, M.; Uchida, H.; Yamashita, H.; Iwasawa, Y.; Watanabe, M. XAFS Characterization of $\mathrm{Pt}-\mathrm{Fe} /$ zeolite
Catalysts for Preferential Oxidation of CO in Hydrogen Fuel Gases. Catal. Lett. 2005, 103, 263-269.

(26) Vannice, M. A.; Garten, R. L. The synthesis of hydrocarbons from $\mathrm{CO}$ and $\mathrm{H}_{2}$ over well-characterized supported PtFe catalysts. J. Mol. Catal. 1976, 1, 201-222.

(27) Xu, H.; Fu, Q.; Yao, Y.; Bao, X. Highly active Pt-Fe bicomponent catalysts for $\mathrm{CO}$ oxidation in the presence and absence of $\mathrm{H}_{2}$. Energy Environ. Sci. 2012, 5, 6313-6320.

(28) Nørskov, J. K.; Bligaard, T.; Rossmeisl, J.; Christensen, C. H. Towards the computational design of solid catalysts. Nat. Chem. 2009, $1,37$.

(29) Stamenkovic, V.; Mun, B. S.; Mayrhofer, K. J.; Ross, P. N.; Markovic, N. M.; Rossmeisl, J.; Greeley, J.; Nørskov, J. K. Changing the activity of electrocatalysts for oxygen reduction by tuning the surface electronic structure. Angew. Chem. 2006, 118, 2963-2967.

(30) Su, H.-Y.; Gu, X.-K.; Ma, X.; Zhao, Y.-H.; Bao, X.-H.; Li, W.-X. Structure evolution of $\mathrm{Pt}-3 \mathrm{~d}$ transition metal alloys under reductive and oxidizing conditions and effect on the $\mathrm{CO}$ oxidation: a firstprinciples study. Catal. Today 2011, 165, 89-95.

(31) Yentekakis, I.; Moggridge, G.; Vayenas, C.; Lambert, R. In situ controlled promotion of catalyst surfaces via NEMCA: the effect of $\mathrm{Na}$ on the Pt-catalyzed CO oxidation. J. Catal. 1994, 146, 292-305.

(32) Harkness, I. R.; Lambert, R. M. Chemisorption and reactivity of nitric oxide on Na-dosed platinum $\{111\}$. J. Chem. Soc., Faraday Trans. 1997, 93, 1425-1429.

(33) Kotobuki, M.; Watanabe, A.; Uchida, H.; Yamashita, H.; Watanabe, M. Reaction mechanism of preferential oxidation of carbon monoxide on $\mathrm{Pt}, \mathrm{Fe}$, and $\mathrm{Pt}-\mathrm{Fe} /$ mordenite catalysts. J. Catal. 2005, 236, 262-269. 